EDITORIAL

\title{
General Practitioners Need Support
}

\author{
Samir Rabbata
}

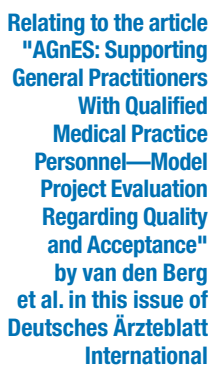

(6) ermany is running out of medical doctors, but fortunately not out of ideas about how to deal with the lack of physicians in both the outpatient and hospital sectors. One such strategy is to relieve the workload of hospital and private practice physicians by using nonmedical personnel. In many hospitals, medical assistants are already assuming tasks that are not of an essentially medical nature. This helps hospitals save both money and physicians' valuable working time. In the outpatient setting too, community nurses have long been a fixture of health care delivery systems, at least in some model regions.

The greater integration of medical practice employees into the provision of health care can improve the level of satisfaction both of physicians and patients, a fact demonstrated by the results of the evaluation of the model project AGnES (community-based, e-health-assisted systemic support for primary care). As follows from the study reported in this issue of Deutsches Ärzteblatt International (1), the majority of GPs participating in the project (38 of 42) found that the AGnES project has the effect of relieving their workload. Similarly, 37 of 42 GPs were of the opinion that the house calls performed by the specially trained practice employees promoted the patients' compliance. Accordingly, 658 of the 667 patients stated that they regarded the qualified personnel as competent persons to whom they could address health-related questions.

\section{Federal scale implementation}

Although an evaluation of objective medical parameters for quality measurement is still awaited, the political authorities have shown themselves to be satisfied with the model project initiated in 2005 by Greifswald University in Mecklenburg-Western Pomerania. Qualified AGnES personnel are now also active in Brandenburg, Saxony, and Saxony-Anhalt. The Government Commissioner for the new federal states, Federal Minister Wolfgang Tiefensee (SPD), has announced that not only is the project to be continued after completion of the test phase on 31 December 2008, it is also to be introduced in the old federal states. The legal basis for this initiative was created by the coalition with the German New Deal for Carers, which in future will allow members of the medical practice team to perform tasks in the medical area and also to make house calls as instructed by the physician. The requirement is now to secure adequate remuneration for these services. However, no agreement has yet been reached by the National Association of Statutory Health Insurance Physicians and the health insurance funds regarding the level of this remuneration.

Independently of the remuneration aspect, some sections of the medical community take a critical view of AGnES but also of model projects such as Verah (Health
Care Assistant in General Practice) or MoPra (Mobile Practice Assistant), fearing a loss of areas of responsibility. Some physicians are also skeptical as to whether certain services should be delegated to the personnel.

\section{Concentration and core tasks}

This year's $111^{\text {th }}$ German Physicians' Congress thus clearly declared that overall therapeutic responsibility must remain with the physician. The delegates also agreed, however, that the changing conditions make it indispensable to integrate the allied health professions to a greater extent in patient management. Physicians therefore need support.

In the evaluation of the AGnES project, study coordinator Prof. Hoffmann and coauthors emphasized that it was not the goal of the project to substitute components of primary medical care delivery with other professional groups. The approach adopted therefore differs from the approachadvocated especially by nursing associations - to completely transfer some areas of medical care with independent budget responsibility. Substitution of medical services of this kind would give rise to considerable problems. For example, patients have an entitlement to treatment at specialist level when receiving services which are the prerogative of medical doctors. The provision of medical services by nursing personnel providing medical services at their own responsibility cannot meet this standard. Liability conflicts would be predestined to occur in the event of harm.

On the other hand, delegating medical services offers two advantages in a situation of dwindling physician resources: in structurally weak regions physicians cooperating with their practice employees can treat more patients and thereby mitigate the negative consequences of the physician shortage. More important, however, is that physicians are then able to concentrate again on their core competences, a situation also likely to make the medical profession more attractive for the rising generation of physicians.

\section{Conflict of interest statement}

The author declares that no conflict of interest exists according to the guidelines of the International Committee of Medical Journal Editors.

\section{REFERENCES}

1. Van den Berg N, Meinke C, Heymann R, Fiß T, Suckert E, Pöller C, Dreier A, Rogalski H, Karopka T, Oppermann R, Hoffmann W: AGnES: Hausarztunterstützung durch qualifizierte Praxismitarbeiter - Evaluation der Modellprojekte: Qualität und Akzeptanz. Dtsch Arztebl Int 2009; 106(1-2): 3-9

\section{Samir Rabbata}

Editor for health and social policy

rabbata@aerzteblattberlin.de 